\title{
Perancangan Jaringan Fiber To The Home (FTTH) Menggunakan Teknologi Gigabyte Passive Optical Network (GPON) pada Mall Park23 Tuban
}

\author{
I Putu Gede Yudha Pratama ${ }^{1}$, G.Sukadarmika ${ }^{2}$, P.K.Sudiarta ${ }^{3}$
}

\begin{abstract}
This network design is planned to be implemented in a new building mall located in Tuban-Bali. The area of the mall is about $6.981 \mathrm{~m}^{2}$. This network design is based on Indihome product $(100 \%$ fiber) that deploy GPON (Gigabyte Passive Optical Network) technology. The design of this network started from calculation of demand and required traffic of each prospective tenant. The tenant was divided into three categories. Then, it was identified that the network required a number of 48 core optical cable for extension from closure to ONT (Optical Network Termination). From the Link Power Budget analyses founded the total attenuation uplink and downlink attenuation was $23,84 \mathrm{~dB}$ and $23,574 \mathrm{~dB}$ respectively. Here also founded the Rise Time Budget around $0,25 \mathrm{~ns}$ for uplink and $0,22 \mathrm{~ns}$ for downlink. Those number were below the standard of the maximum allowable rise time i.e 0,5833 ns.
\end{abstract}

Intisari- Perancangan jaringan ini berpusat pada sebuah mall baru yang akan dibangun pada daerah Tuban, Bali. Yang dimana mall berada pada pada luas tanah $6,981 \mathrm{~m}^{2}$. Perancangan ini menggunakan sistem IndiHome (100\% fiber) dengan menggunakan GPON (Gigabyte Passive Optical Network) sebagai teknologinya. Perancangan jaringan ini, dimulai dengan perhitungan demand dan menghitung kebutuhan traffik tiap calon tenant yang akan dibagi menjadi 3 kategori jenis tenant. Dilanjutkan dengan proses merancang struktur jaringan yang dimulai dari penyambungan kabel pada closure sebanyak 48 core hingga sampai pada ONT (Optical Network Termination). Hasil analisis dengan menggunakan parameter Power Link Budget diperoleh total redaman untuk uplink dan downlink masingmasing sebesar 23,84 dB dan 23,574 dB. Margin Daya didapat sebesar 4,16 $\mathrm{dBm}$. Sedangkan, Rise Time Budget diperoleh sebesar 0,25 ns untuk uplink dan 0,22 ns untuk downlink. Nilai tersebut masih dibawah standard maksimum rise time yaitu sebesar 0,5833 ns.

Kata Kunci-Perancangan jaringan, fiber optik, triple play service

\section{PENDAHULUAN}

Perkembangan pemanfataan layanan teknologi informasi dan komunikasi telah menyentuh hampir semua kehidupan masyarakat.

\footnotetext{
${ }^{1}$ Mahasiswa, Nama Jurusan Teknik Elektro dan Komputer Fakultas Teknik Universitas Udayana, Kampus Bukit Jimbaran, Badung, Bali., 80361 INDONESIA (tlp: 0361-555225; fax: 03614321982; e-mail: pratama.yudha007@gmail.com )

2,3 Dosen, Jurusan Teknik Elektro dan KomputerFakultas TeknikUniversitasUdayana, Jln. Jalan Kampus Bukit Jimbaran 80361 INDONESIA (telp: 0361-703315; fax: 0361-4321; e-mail: sukadarmika@unud.ac.id)
}

effective. Dilihat dari segi pengiriman data, media tembaga masih jauh terlampaui dibandingan media transmisi fiber optik yang mampu mengirimkan data hingga 2,5 Gbps [1].

Pentransmisian fiber optik hingga menuju pelanggan atau FTTH (Fiber To The Home) semakin digalakkan untuk masyarakat, baik itu migrasi (mengganti dari tembaga menjadi fiber optik) atau perancangan jaringan baru. Dengan menggunakan teknologi GPON (Gigabyte Passive Optical Network).

Di daerah Tuban, akan dibangun sebuah mall 3 lantai yang memiliki kapasitas 96 blok bagi para pelanggan yang bernama mall Park23 yang memiliki luas tanah sekitar $6.981 \mathrm{~m}^{2}$ yang akan dipasang langsung media transmisi fiber optic hingga menuju pelanggan atau FTTH. Kondisi bangunan mall Park23 belum terdapat perangkat jaringan komunikasi yang memadai.

Dengan bantuan salah satu vendor mall Park23, peneliti melakukan perancangan jaringan FTTH di area bangunan mall. Yang sebelumnya, penulis melakukan penelusuran dari beberapa studi terkait mengenai metode perancangan jaringan sebagai acuan dalam melakukan perancangan jaringan. Proses diawali dengan perhitungan demand beserta kebutuhan traffik pelanggan, lalu dilanjutkan dengan tahap struktur perancangan awal jaringan (penentuan perangkat serta spesifikasinya dan kebutuhannya), setelah itu menganalisa hasil perancangan menggunakan parameter Power Link Budget dan Rise Time Budget.

Dalam penelitian ini, permasalahan tentu akan ada dimana dalam operasional perancangan ini membutuhkan layanan TIK (Telekomunikasi dan Komunikasi). Untuk itu, perlu dilakukan kajian perencanaan jaringan agar infrastruktur yang dibangun sesuai dengan kebutuhannya. Perancangan jaringan ini diharapkan mampu menjadi kajian teknis atau acuan bagi pengembang mall atau vendor untuk pembangunan perancangan jaringan pada bangunan mall Park23 ini.

\section{TINJAUAN PUSTAKA}

\section{A. Perhitungan Demand}

Perhitungan demand disini merupakan suatu proses perhitungan dimana data yang dihitung merupakan data yang ada pada waktu sekarang untuk mengetahui suatu kebutuhan kapasitas bandwidth di suatu tempat [2]. Pada Tabel 1 menunjukkan standar kapasitas per layanan (triple play service). 
TABEL I

STANDAR KAPASITAS PER LAYANAN (TRIPLE PLAY SERVICE)

\begin{tabular}{|c|c|}
\hline \multicolumn{2}{|c|}{$\begin{array}{c}\text { Standar Kapasitas per Layanan (Triple } \\
\text { Play Service) }\end{array}$} \\
\hline Voice & $1024 \mathrm{Kbps}$ \\
\hline Video & $7680 \mathrm{Kbps}$ \\
\hline Internet & $15360 \mathrm{Kbps}$ \\
\hline
\end{tabular}

Selain menggunakan standar pada Tabel I, dalam perhitungan demand menggunakan standar lain untuk layanan voice [3] dan layanan video [4], berfungsi untuk membandingkan hasil dari demand pelanggan dengan standar terkait agar tidak berada di bawah kapasitas standar bitrate yang telah disediakan.

\section{B. Kebutuhan Traffik}

Perhitungan kebutuhan traffic berguna untuk mengetahui kategori pelanggan yang paling banyak membutuhkan kebutuhan bandwidth dalam sebuah bangunan atau gedung. Selain itu, tujuan lain perhitungan traffic adalah meningkatkan faktor ekonomis [5].

\section{FTTH (Fiber To The Home)}

Arsitektur jaringan fiber optik secara umum dapat dibagi menjadi 4 bagian yang memiliki fungsi dan kebutuhan tersendiri [6].

Teknologi FTTH (Fiber To The Home) menggunakan topologi jaringan Point To Multipoint dimana jaringan dimulai dari satu titik menuju ke titik yang banyak [7]. Sebelum FTTH, teknologi yang digunakan adalah MSAN yang dimana, kabel fiber hanya digunakan dari OLT menuju MSAN dan sisanya menggunakan kabel cooper atau tembaga. Untuk FTTH, semua kabel cooper yang menjadi penghubung diganti dengan fiber optik [7]. Perbandingan teknologi ini dapat dilihat pada Gambar 1.

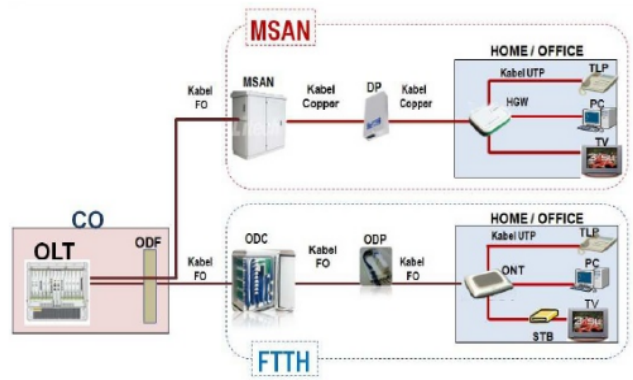

Gambar 1: Perbandingan Teknologi MSAN dan FTTH (Sumber: Adrian,dkk, 2013)

\section{E. Definisi GPON (Gigabyte Passive Optical Network)}

GPON ( Gigabyte Passive Optical Network ) adalah suatu teknologi akses optik dengan kecepatan 2,488 Gbps yang terstandarisasi oleh ITU-T G.984. Yang dimana teknologi ini telah mengalami beberapa evolusi teknologi sebelum menjadi GPON [8]. Teknologi GPON menawarkan suatu jaringan yang cost-efective, flexible dalam provisioning voice maupun data service yang reliable berbasis pada optical access network.

I Putu Gede Yudha Pratama: Perancangan Jaringan Fiber To ...
Gambar 2: menunjukan konfigurasi sistem GPON pada dasarnya dibagi menjadi 3 bagian, yaitu :

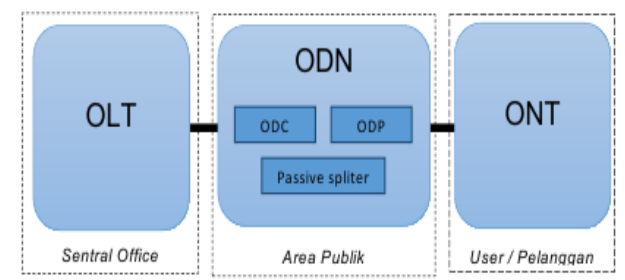

Gambar 2: Konfigurasi Jaringan Sistem Teknologi GPON

\section{OLT (Optical Line Termination)}

OLT menyediakan antarmuka antara sistem PON (Passive Optical Network) terhadap service provider (voice, video dan internet) [1].

2. ODN (Optical Distribution Network)

ODN merupakan jaringan optik antara OLT sampai perangkat ONT. Menyediakan transmisi optik dari OLT terhadap pelanggan. Menggunakan komponen optik passive sebagai sistem transmisi [1].

Dalam ODN, terdapat 3 perangkat yang digunakan, yaitu : ODC (Optical Distribution Cabinet), ODP (Optical Distribution Point), ONT (Optical Network Termination) dan Passive Splitter [1].

3. ONT (Optical Network Termination) ONT menyediakan interface antara jaringan optik dengan pelanggan. Sinyal optik yang ditransmisikan melalui ODN diubah oleh ONT menjadikan sinyal elektrik yang diperlukan untuk layanan pelanggan [1].

\section{E. Power Link Budget}

Power Link Budget dihitung sebagai syarat agar link yang digunakan dayanya tidak melebihi batas ambang dari daya yang dibutuhkan menurut standar yang ditentukan sesuai dengan ITU-T G.984 sebesar 28 dB. Pada standar realita perhitungan Power Link Budget di lapangan, perangkat dapat bekerja dengan baik pada nilai $25 \mathrm{~dB}$ [9]. Untuk menghitung parameter Power Link Budget dapat dihitung dengan menggunakan Persamaan (1) dan Persamaan (2).

$\alpha_{\mathrm{tot}=\mathrm{L}} \alpha_{\mathrm{serat}}+\mathrm{Nc} . \alpha_{\mathrm{c}+} \mathrm{Ns} . \alpha_{\mathrm{s}+} \mathrm{Sp}+$ redaman instalasi

$\mathrm{M}=(\mathrm{Pt}-\mathrm{Pr})-\alpha_{\mathrm{total}}-\mathrm{SM}$

Dimana:

$\mathrm{Pt}$ = Daya keluaran sumber optik $(\mathrm{dBm})$

$\operatorname{Pr}=$ Sensitivitas daya maksimum detektor $(\mathrm{dBm})$

$\mathrm{SM}=$ Safety margin, berkisar 6-8 dB

$\alpha_{\mathrm{tot}}=$ Redaman Total sistem (dB)

$\mathrm{L}=$ Panjang serat optik $(\mathrm{Km})$

$\alpha_{c}=$ Redaman Konektor ( $\left.\mathrm{dB} / \mathrm{buah}\right)$

$\alpha_{\mathrm{s}}=$ Redaman sambungan ( $\mathrm{dB} /$ sambungan)

$\alpha_{\text {serat }}=$ Redaman serat optik ( $\left.\mathrm{dB} / \mathrm{Km}\right)$

Ns = Jumlah sambungan

$\mathrm{Nc}=$ Jumlah konektor

$\mathrm{Sp}=$ Redaman Splitter $(\mathrm{dB})$

p-ISSN:1693 - 2951; e-ISSN: 2503-2372 


\section{F. Rise Time Budget}

Rise Time Budget merupakan metode untuk menentukan batasan disperse suatu link serat optik. Metode ini sangat berguna untuk menganalisa system transmisi digital. Tujuan dari metode ini adalah untuk menganalisa apakah unjuk kerja jaringan secara keseluruhan telah tercapai dan mampu memenuhi kapasitas kanal yang diinginkan. Standar maksimum rise time budget dan bit rate NRZ yaitu $0,5833 \mathrm{~ns}$ dan 0,2917 ns. Untuk menghitung Rise Time budget dapat dihitung dengan menggunakan Persamaan (3).

$t_{\text {total }}=\left(t_{t x}^{2}+t_{\text {intramodal }}{ }^{2}+t_{\text {intermodal }}{ }^{2}+t_{r x}^{2}\right)^{1 / 2}$

Dimana :

$\mathrm{t}_{\mathrm{tx}}=$ Rise time transmitter $(\mathrm{ns})$

$\mathrm{t}_{\mathrm{rx}}=$ Rise time receiver $(\mathrm{ns})$

$\mathrm{t}_{\text {intermoda }}=$ bernilai nol (untuk serat optic single mode)

$\mathrm{t}_{\text {intramodal }}=\mathrm{t}_{\text {material }}+\mathrm{t}_{\text {waveguide }}$

$\mathrm{t}_{\text {material }}=\Delta \sigma \times \mathrm{L} \times \mathrm{Dm}$

$\mathrm{t}_{\text {waveguide }}=\frac{L}{C}\left[\mathrm{n} 2+\mathrm{n} 2 \Delta \mathrm{d}\left(\frac{v b}{d v}\right)\right]$

$\Delta_{S}=\frac{n 1-n 2}{n 1}$

$u_{c}=2 v^{1 / 2}$

$d\left(\frac{v b}{d v}\right)=1+\left(u_{c}^{2}+v^{2}\right)$

$\Delta \sigma=$ Lebar Spektral $(\mathrm{nm})$

$\mathrm{L}=$ Panjang serat optik $(\mathrm{Km})$

$\mathrm{Dm}=$ Dispersi Material $(\mathrm{ps} / \mathrm{nm} . \mathrm{Km})$

$\mathrm{N} 2$ = Indeks bias selubung

$\mathrm{C}=$ kecepatan rambat cahaya $3 \times 10^{8}$

$\mathrm{v}=\frac{2 \pi \mathrm{xa}}{\lambda} \times \mathrm{n}_{1 \times}(2 \times \Delta \mathrm{s}) 1^{12}$

$\mathrm{a}=$ Jari-jari inti

$\mathrm{n} 1=$ indeks bias inti

$\mathrm{n} 2=$ Indeks bias selubung

\section{METODE PENELITIAN}

\section{A. Tahapan Penelitian}

Penelitian ini dilakukan di daerah Tuban, Bali pada bulan Februari 2015 sampai dengan November 2015. Pada tahapan pertama, dilakukan studi literatur lalu mengkaji literatur. Lalu dilanjutkan dengan mengumpulkan data-data pelanggan (permintaan layanan awal) yang berguna untuk dapat melakukan perhitungan demand dan mengetahui kebutuhan traffik yang dalam proses ini, penulis akan membagi pelanggan menjadi 3 bagian kategori menurut jenis pelanggan untuk mempermudah melakukan proses perhitungan dan dilanjutkan dengan pengumpulan data-data perancangan. Setelah itu, melakukan perancangan awal (penentuan perangkat serta spesifikasinya dan analisis kebutuhannya) dalam perancangan. Lalu menyusun daftar perangkat yang akan digunakan dalam perancangan serta konfigurasi jaringan setelah melakukan analisis.

Langkah berikutnya adalah mengumpulkan data parameter perhitungan yang didapat dari data jarak antar perangkat dan spesifikasi perangkat. Setelah itu dilanjutkan dengan tahapan analisis dengan membandingkan hasil perhitungan dengan standar yang berlaku. Pada Gambar 3: menunjukkan alur analisis perancangan jaringan secara keseluruhan.

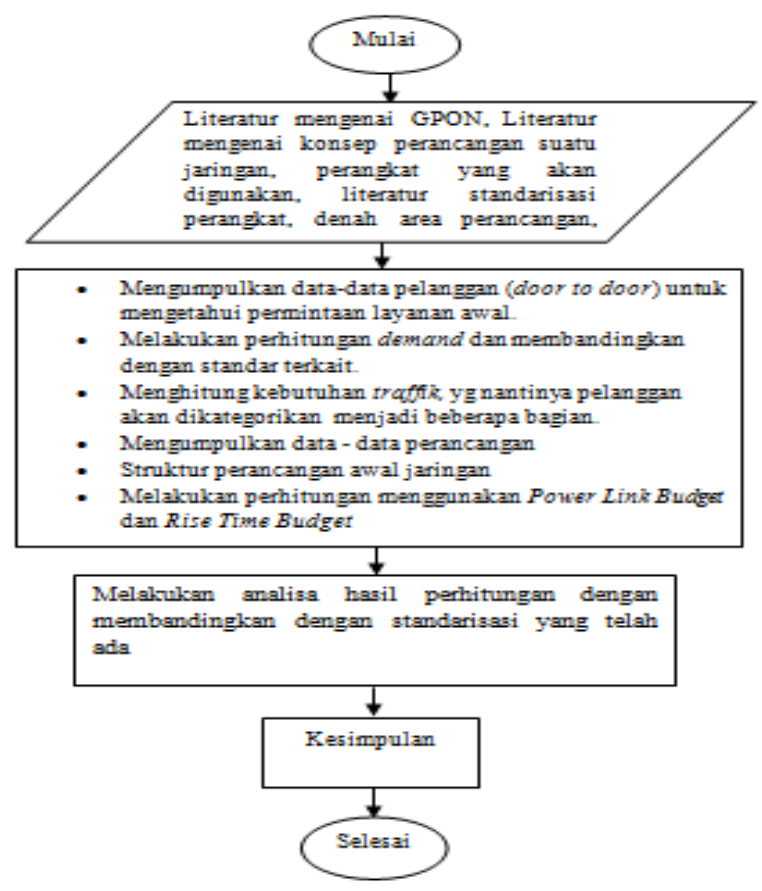

Gambar 3: Alur Analisis Perancangan Jaringan

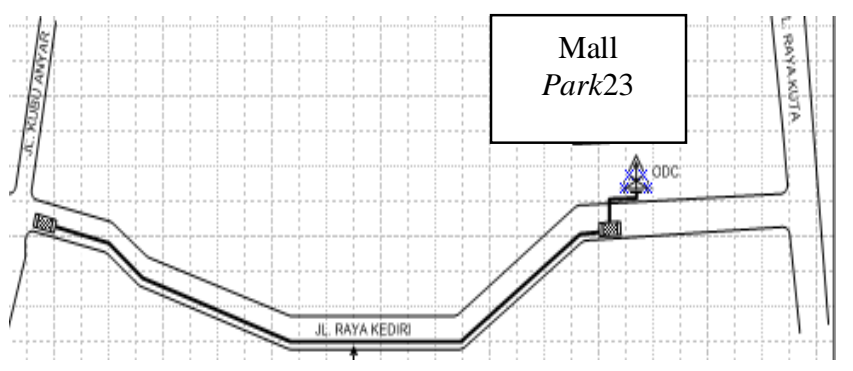

Gambar 4: Denah Lokasi Perancangan Jaringan

Pada Gambar 4: menunjukkan denah lokasi perancangan (jalur umum kabel feeder) pada jalan Kediri, Tuban, Bali. Yang dimana, pada Gambar tersebut perancangan akan dimulai dari persimpangan jalan kediri, dewi sartika kubu anyar (penyambungan kabel fiber pada closure) hingga kembali menuju perangkat ODC (Optical Distribution Cabinet) pada sisi mall Park23. 


\section{IV.HASIL DAN PEMBAHASAN}

\section{A. Perhitungan Demand}

Berikut merupakan hasil dari perhitungan demand per layanan yang telah dilakukan perhitungan dan dibandingkan dengan kapasitas per layanan pada Tabel 1 dan standar yang ada dengan jumlah pelanggan sebanyak 41 pelanggan.

\section{Voice}

Menurut standar kapasitas per layanan pada Tabel 1 untuk layanan ini disediakan standar bitrate 1024 kbps. Pada perhitungan kebutuhan bitrate codec G.711 pada persamaan 1, didapatkan hasil $81,98 \mathrm{kbps}$ untuk 1 ONT (terdapat 2 port voice). Terdapat permintaan terbanyak untuk layanan ini sebanyak 4 kanal. Sehingga 4 kanal voice dikalikan dengan kebutuhan bitrate codec G.711, didapatkan hasil 327,92 kbps.

\section{Video}

Menurut standar kapasitas per layanan pada Tabel 1 untuk layanan ini disediakan standar bitrate $7680 \mathrm{kbps}$. Pada Gambar 1: menunjukkan standar H.264 yang dimana dibutuhkan bitrate untuk video (HD) dengan resolusi 1080p yaitu 5,12 Mbps.

\section{Internet}

Menurut standar kapasitas per layanan pada Tabel 1 untuk layanan ini disediakan standar bitrate $15360 \mathrm{kbps}$. Sehingga permintaan pelanggan sebesar $10 \mathrm{Mbps}$ dapat dilayani dengan baik, dikarenakan masih berada di bawah kapasitas standar bitrate yang disediakan.

\section{B. Kebutuhan Traffik}

Pada Tabel II, akan menunjukkan hasil akhir mengenai data pelanggan yang telah dikategorikan menjadi 3 bagian. Selanjutnya, layanan (voice, video dan internet) akan dijumlahkan per pelanggan untuk mengetahui total kebutuhan bitrate menggunakan standar kapasitas per layanan pada Tabel 1.

TABEL II

KEBUTUHAN TRAFFIK

\begin{tabular}{|c|c|c|c|}
\hline No & Kategori & $\begin{array}{c}\text { Total } \\
\text { Pelanggan }\end{array}$ & $\begin{array}{c}\text { Total } \\
\text { Kebutuhan }\end{array}$ \\
\hline 1 & Makanan dan Minuman & 12 Tenant & $183,4 \mathrm{Mbps}$ \\
\hline 2 & Fashion and Lifestyle & 25 Tenant & $321,4 \mathrm{Mbps}$ \\
\hline 3 & Hiburan & 4 Tenant & $63,9 \mathrm{Mbps}$ \\
\hline
\end{tabular}

\section{Daftar Perangkat yang Dibutuhkan}

Pada Tabel III menunjukkan daftar perangkat yang dibutuhkan dalam perancangan jaringan ini. Yang dimana, pada perancangan ini dibangun perangkat ODC (Optical Distribution Cabinet) baru di sisi Mall Park23. Dikarenakan tidak adanya perangkat ODC terdekat sesuai kondisi sebelumnya dan pembangunan perangkat ini dapat I Putu Gede Yudha Pratama: Perancangan Jaringan Fiber To ... memudahkan instalasi jaringan (penarikan kabel) untuk daerah terdekat mall Park23 kedepan. Dengan analisis, jumlah core masuk ke perangkat ODC sebanyak 48 core, sehingga 48 × 4 × $8=1536$. Nilai 1536 ini merupakan jumlah total pelanggan yang dapat terlayani pada perangkat ODC ini. Pada perancangan jaringan di mall Park23 ini, menggunakan kabel sebanyak 6 core dari jumlah total 48 core, sehingga $6 \mathrm{x}$ 4 x $8=192$ pelanggan. Jadi total perhitungan calon pelanggan yang dapat dilayani perangkat baru ini setelah digunakan 6 core untuk melayani mall Park23 sebanyak, 1536 - $192=$ 1344 calon pelanggan. Hal ini akan sangat berpengaruh bagi vendor atau penyedia jasa layanan komunikasi dalam hal efective cost dan juga dalam segi instalasi kedepan.

Pada point 5 dan 7 pada Tabel III, penggunaan passive splitter 1:8 penggunaannya digandakan, dengan analisis pihak mall Park23 menginginkan instalasi yang rapi dengan kapasitas tempat perangkat ODP (Optical Distribution Point) yg sedikit. Sehingga 1 perangkat ODP dipasangkan 2 buah passive splitter 1:8, yang dimana 1 perangkat ini dapat melayani 16 pelanggan.

TABEL III

DAFTAR PERANGKAT YANG DIBUTUHKAN

\begin{tabular}{|c|c|c|c|}
\hline No & Perangkat & Jumlah & Keterangan \\
\hline 1 & OLT & 1 unit & 1 unit \\
\hline 2 & Kabel Feeder & $\begin{array}{l}2 \text { buah }= \\
2,744 \mathrm{~km}\end{array}$ & $\begin{array}{l}\text { STO-Closure }=1,544 \mathrm{~km} \\
\text { Closure }-\mathrm{ODC}=1,200 \mathrm{~km}\end{array}$ \\
\hline 3 & ODC & 1 unit & 1 unit \\
\hline 4 & Ps $1: 4$ & 9 buah & 6 digunakan, 3 cadangan \\
\hline 5 & Ps $1: 8$ & 20 buah & $\begin{array}{l}\text { Digunakan 1 ODP } 2 \text { PS 1:8 } \\
(\mathrm{ODP}=10)\end{array}$ \\
\hline 6 & $\begin{array}{c}\text { Kabel } \\
\text { Distribusi }\end{array}$ & $\begin{array}{c}4=1,375 \\
\mathrm{~km}\end{array}$ & $4=1,375 \mathrm{~km}$ \\
\hline 7 & ODP & 10 unit & 10 unit \\
\hline 8 & Drop Kabel & 103 & 103 \\
\hline 9 & ONT & 103 unit & $\begin{array}{l}96 \text { digunakan sesuai } \\
\text { rencana perancangan, } 7 \\
\text { cadangan }\end{array}$ \\
\hline 11 & Konektor SC & 206 buah & $\begin{array}{l}1 \text { pelanggan }=2 \text { buah } \\
192 \text { digunakan, } 14 \\
\text { cadangan }\end{array}$ \\
\hline 12 & Sambungan & 485 buah & 485 buah \\
\hline
\end{tabular}

\section{Konfigurasi Jaringan}

Gambar 5: menunjukkan konfigurasi jaringan menggunakan teknologi GPON yang dimulai dari STO Kuta menuju ODC (Optical Distribution Cabinet) daerah perancangan (mall Park23) yang ditarik kabel sebanyak 48 core setelah melakukan penyambungan kabel pada closure. Dari ODC (Optical Distribution Cabinet) menggunakan passive splitter 1:4 yang menghasilkan output 4 kabel distribusi yang akan didistribusikan untuk menyalurkan ke masing-masing ODP (Optical Distribution Point) yang setelah itu akan disalurkan lagi menuju ONT (Optical Network Termination) dengan menggunakan passive splitter 1:8 dari

p-ISSN:1693 - 2951; e-ISSN: 2503-2372 
output ODP (dengan menggunakan sistem passive splitter 1:8 dikalikan 2).

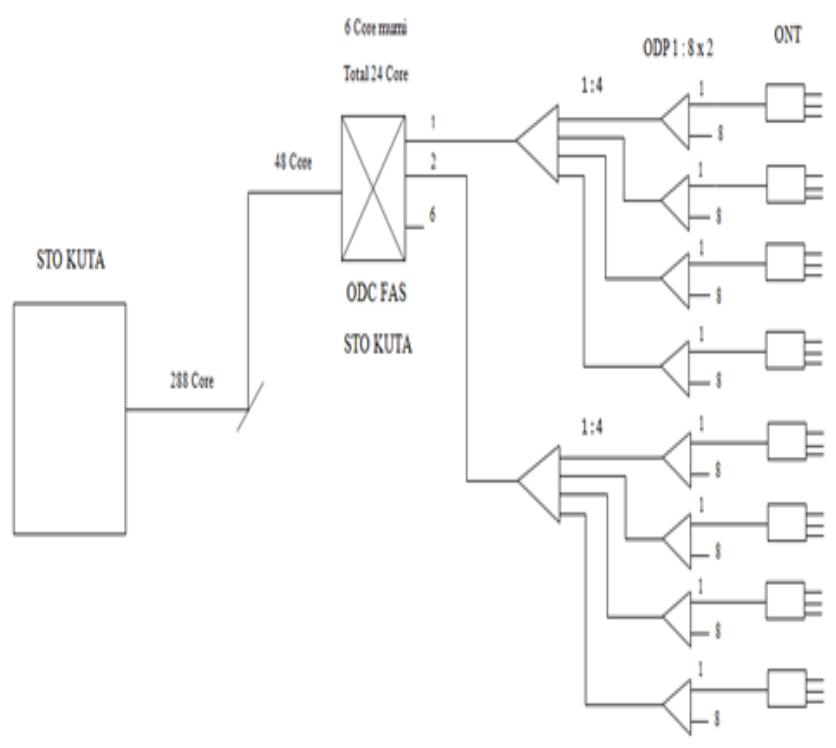

Gambar 5: Konfigurasi Jaringan Mall Park23

\section{E. Analisis Hasil Perancangan}

Pada Gambar 6: menunjukkan gambaran jarak dari perangkat ODC (Optical Distribution Cabinet) menuju perangkat ODP (Optical Distribution Point), dimana pada kabel distribusi 1 terdapat 4 perangkat ODP, kabel distribusi 2 dan 3 terdapat masing - masing 3 perangkat ODP dan kabel distribusi 4 berada pada OTB (Optical Termination Box) yang terletak pada lantai dasar. Jarak antar perangkat akan diukur sebagai data melakukan perhitungan.

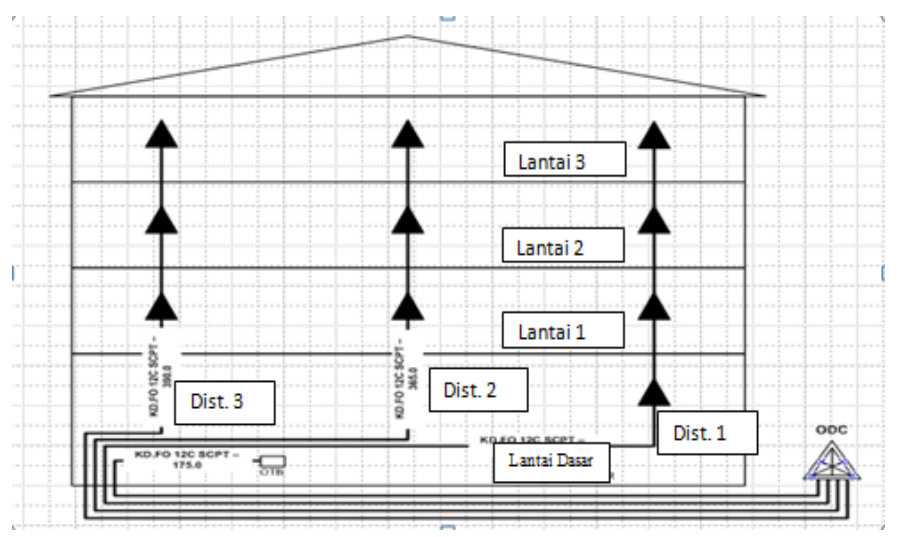

Gambar 6: Jarak perangkat ODC (Optical Distribution Cabinet) menuju ODP (Optical Distribution Point)

Pada Tabel IV menunjukkan data jarak antar perangkat (STO - ONT) yang akan digunakan dalam perhitungan menggunakan parameter analisis kelayakan. Setelah melakukan pengukuran langsung di lapangan, penulis mendapatkan jarak terjauh antar perangkat dimana hasil jarak terjauh antar perangkat berada pada distribusi 3 .
TABEL IV

JARAK ANTAR PERANGKAT

\begin{tabular}{|c|c|c|c|}
\hline \multicolumn{2}{|c|}{ Jarak STO - Closure } & \multicolumn{2}{|c|}{ Jarak Closure - ODC } \\
\hline \multicolumn{2}{|c|}{$1,544 \mathrm{~km}$} & \multicolumn{2}{|c|}{$1,200 \mathrm{~km}$} \\
\hline \multicolumn{4}{|c|}{ Jarak ODC - ODP Terjauh } \\
\hline Dist. 1 & Dist. 2 & Dist. 3 & Dist. 4 \\
\hline $0,445 \mathrm{~km}$ & $0,365 \mathrm{~km}$ & $0,390 \mathrm{~km}$ & $0,175 \mathrm{~km}$ \\
\hline \multicolumn{4}{|c|}{ Jarak ODP - ONT Terjauh } \\
\hline Dist. 1 & Dist. 2 & Dist. 3 & Dist. 4 \\
\hline $50 \mathrm{~m}$ & $20 \mathrm{~m}$ & $75 \mathrm{~m}$ & \\
\hline
\end{tabular}

TABEL V

HASIL ANALISIS PERHITUNGAN

\begin{tabular}{|c|c|c|c|c|c|}
\hline No & Parameter & Gelombang & Hasil & Standarisasi & Ket. \\
\hline \multirow{2}{*}{1} & Power Link & $\begin{array}{c}1310 \mathrm{~nm} \\
(\text { Uplink })\end{array}$ & $\begin{array}{c}23,84 \\
\mathrm{~dB}\end{array}$ & $28 \mathrm{~dB}$ & Layak \\
\cline { 3 - 6 } & $\begin{array}{c}1490 \mathrm{~nm} \\
(\text { Downlink })\end{array}$ & $\begin{array}{c}23,574 \\
\mathrm{~dB}\end{array}$ & $28 \mathrm{~dB}$ & Layak \\
\hline \multirow{2}{*}{2} & $\begin{array}{c}\text { Rise Time } \\
\text { Budget }\end{array}$ & $\begin{array}{c}1310 \mathrm{~nm} \\
(\text { Uplink })\end{array}$ & $0,25 \mathrm{~ns}$ & $\begin{array}{c}0,5833 \\
\mathrm{~ns} / 0,2917 \mathrm{~ns}\end{array}$ & Layak \\
\cline { 3 - 6 } & $\begin{array}{c}1490 \mathrm{~nm} \\
\text { (Downlink })\end{array}$ & $0,25 \mathrm{~ns}$ & $\begin{array}{c}0,5833 \\
\mathrm{~ns} / 0,2917 \mathrm{~ns}\end{array}$ & Layak \\
\hline
\end{tabular}

Tabel V menunjukkan hasil perhitungan setelah melakukan perhitungan menggunakan Persamaan (1) dan Persamaan (2) pada parameter Power Link Budget dan menggunakan Persamaan (3) pada parameter Rise Time Budget, didapatkan hasil setelah dilakukan perbandingan antara hasil pengukuran dan standar terkait hasil tersebut mengindikasikan bahwa nilai memenuhi kelayakan sehingga perancangan jaringan dikategorikan bagus.

\section{Kesimpulan}

Berdasarkan hasil analisis pada perhitungan demand, didapatkan hasil yang masih berada dibawah kapasitas standar bitrate yang disediakan. Pada tahap kebutuhan traffik, didapatkan hasil sebesar 183,4 Mbps "makanan dan minuman", 321,4 Mbps "fashion and lifestyle" dan 63,9 Mbps "hiburan".

Pada struktur rancangan jaringan dimulai dengan melakukan proses penyambungan kabel pada closure untuk ditarik kabel feeder sebesar 48 core. Dibangun 1 unit perangkat ODC dengan menggunakan passive splitter 1;4 sebanyak 9 buah (6 on dan 3 off). Output dari ODC adalah 4 kabel distribusi yang menggunakan 6 core murni untuk menghidupkan 10 unit ODP yang masing-masing menggunakan sepasang passive splitter 1:8 (20 buah). 1 ODP mampu memfasilitasi 16 pelanggan.

Berdasarkan hasil analisis jaringan yang dimulai dari STO Kuta hingga pelanggan dengan jarak terjauh $\pm 3,239 \mathrm{~km}$, didapatkan hasil beberapa parameter yaitu : Pada power link budget memiliki redaman total pada jarak terjauh sebesar 23,84 dB untuk uplink dan 23, $574 \mathrm{~dB}$ untuk downlink. Hal ini masih berada dalam toleransi yang ditetapkan ITU-T G.984 
sebesar $28 \mathrm{~dB}$. Untuk nilai margin daya, didapatkan nilai sebesar 4,16 dBm untuk uplink dan 4,426 dBm untuk downlink. Hasil margin daya tersebut masih dalam kategori bagus karena nilai masih berada diatas 0 (nol). Hal ini mengindikasikan bahwa nilai memenuhi kelayakan power link budget. Pada rise time budget untuk uplink menghasilkan total waktu sebesar $0,25 \mathrm{~ns}$. Untuk downlink menghasillkan total waktu sebesar 0,22 ns. Nilai ini masih berada dibawah nilai maksimum rise time sebesar $0,5833 \mathrm{~ns}$ dan bitrate NRZ yang telah ditentukan sebesar 0,2917 ns.

\section{REFERENSI}

[1] Indonesia, Telkom, Materi Pelatihan Design FTTx (Fiber To The "x"). Makassar: Telkom Indonesia, 2013.

[2] Ramadhan, Muhamad, Hambali, Akhmad, dan Uripno, Bambang,'Perancangan Jaringan Akses Fiber To The Home (FTTH) Menggunakan Teknologi Gigabyte Passive Optical Network (GPON) Di Perumahan Setraduta Bandung,'’. 2012.

[3] Paramarta, Eka, “Analisis Kualitas Jaringan Lokal Akses Fiber Optik Pada Indihome PT. Telkom Di Wilayah Jimbaran,” Teknologi Elektro, Vol., No., Januari-Juni 2016.

[4] Patterson, Jason. (2012) Video Encoding Settings For H.264 Excellence. [Online]. Available: http://www.lighterra.com/papers/videoencodingh264/

[5] Fauzy, Rahmat, "Pengantar Peramalan Dalam Telekomunikasi,". Fakultas Teknik Universitas Sumatra Utara. 2004.

[6] Lestari, Annisa Ayu, "Perancangan Jaringan Fiber To The Home Perumahan Nataendah Kopo DenganOptisystem,', 2015.

[7] Adrian. Idham, Tadarus. Muhamad, Wildan,"Analisis Dan Perancangan Jaringan FTTH (Fiber To The Home) Dengan Teknologi GPON Di PT Telkom, Tbk,", 2013.

[8] Oka Pramundia, Ngakan, Analisis Pengukuran Kualitas Jaringan GPON Pada Layanan IPTV PT. Telkom Di Wilayah Bali Selatan. Fakultas Teknik: Universitas Udayana, 2015.

[9] Indonesia, Telkom, FTTH Readyness. Telkom Corporate University. 2015 . 